\title{
Preparation of capacitor's electrode from cassava peel waste
}

\author{
Andrian Evan Ismanto, Steven Wang, Felycia Edi Soetaredjo, Suryadi Ismadji * \\ Department of Chemical Engineering, Widya Mandala Surabaya Catholic University Kalijudan 37, Surabaya 60114, Indonesia
}

\section{A R T I C L E I N F O}

\section{Article history:}

Received 10 October 2009

Received in revised form 12 December 2009

Accepted 16 December 2009

Available online 25 January 2010

\section{Keywords:}

Activated carbon

Electric Double Layer Capacitor

Cassava peel

Surface modification

Electrode material

\begin{abstract}
A B S T R A C T
Cassava peel was used as the precursor for activated carbon-based electrodes which were then prepared by a combination of chemical and physical activation. The surface of the activated carbon was treated with the oxidative chemical agents, 98 wt.\% $\mathrm{H}_{2} \mathrm{SO}_{4}, 65 \mathrm{wt} . \% \mathrm{HNO}_{3}$, and $30 \mathrm{wt} . \% \mathrm{H}_{2} \mathrm{O}_{2}$ solutions. The surface modification had no significant effect on the specific surface area, but greatly influenced the surface chemistry of the carbons. The presence of oxygen-containing groups increased the polarity and hydrophilicity of activated carbon, and thus improved the performance of the activated carbon-based electrode. As a result, the specific capacitance of the $\mathrm{HNO}_{3}$ modified AC-electrode reached $264.08 \mathrm{~F} / \mathrm{g}$, an increase of $72.6 \%$ compared to the original one. The results indicate that cassava peel waste can potentially be applied as a raw material for the production of low cost-high performance activated carbon electrode materials for Electric Double Layer Capacitors (EDLCs).
\end{abstract}

(c) 2010 Elsevier Ltd. All rights reserved.

\section{Introduction}

Electric Double Layer Capacitors (EDLCs), also known as supercapacitors, are a new breakthrough in energy storage device technology that have attracted considerable attention because of their high capacitance, power delivery performance and long life cycle (Tamai et al., 2005; Yansu et al., 2008). With all of these advantages, EDLCs have been widely used in the information technology industry, for electronic devices, electric vehicles, and military equipment where high power energy storage device with an ever-decreasing size is needed (Yafei et al., 2008).

One of the most important components of a supercapacitor is the electrode. For EDLC electrodes, the most common used materials are metal oxides, polymers, and porous materials such as activated carbons and carbon aerogels. Furthermore, new carbon materials such as carbon nanotubes have been developed as electrode material, but complicated preparation and high cost led to difficulties in their practical application (Yafei et al., 2008). Activated carbon is a suitable material for the production of electrode for supercapacitors, because of its high surface area, good thermal and electric conductivity, good anti-causticity, high stability, low cost, and commercially available (Yafei et al., 2008). The application of activated carbons and other carbonaceous materials as the electrode of EDLCs has been studied by various research groups (Centeno and Stoeckli, 2006; Chmiola et al., 2006; Feng-Chin et al., 2006; Frackowiak and Beguin, 2001; Kim et al., 2006; Morishita

\footnotetext{
* Corresponding author. Tel.: +62 31 3891264; fax: +62 313891267 .

E-mail address: suryadiismadji@yahoo.com (S. Ismadji).
}

et al., 2006; Tamai et al., 2005; Tashima et al., 2007; Xu et al., 2008; Yafei et al., 2008; Yansu et al., 2008).

Theoretically, the higher the surface area, the larger the capacitance; however, several studies reported that the specific capacitance was not proportional to the surface area of activated carbon, because both pore structure and surface chemistry have influence on the capacitive behavior of carbon materials ( $\mathrm{Qu}$ and Shi, 1998; Yafei et al., 2008). Surface modifications to introduce and even increase the functional groups on the activated carbon surface have a significant influence on the performance of carbon electrodes (Tashima et al., 2007; Yafei et al., 2008; Yoshida et al., 1990). Yafei et al. (2008) reported that the specific capacitance of the carbon modified with $65 \% \mathrm{HNO}_{3}$ reached $250 \mathrm{~F} / \mathrm{g}, 72.4 \%$ higher than that of the original carbon (Yafei et al., 2008).

Cassava is known as one of the most important agricultural commodities in Indonesia (Sudaryanto et al., 2006). Cassava is used as raw material for the production of cassava starches and traditional foods and cakes. Its leaves can be utilized as vegetables or natural medicine since it contains high amounts protein and other bioactive compounds, and its wood is often used as firewood for cooking. Cassava starch processing produces a large amount of solid wastes (cassava peels), and direct discharge of these solid wastes causes environmental problems. Utilization of cassava peels as precursor for activated carbon with a high surface area has already been demonstrated (Sudaryanto et al., 2006).

In this study, cassava peel was used as the raw material for the preparation of a capacitor's electrode. The cassava peel activated carbons were modified by surface treatment with $\mathrm{HNO}_{3}, \mathrm{H}_{2} \mathrm{SO}_{4}$, and $\mathrm{H}_{2} \mathrm{O}_{2}$, to improve their surface chemistry. The influence of the surface modifications on the capacitance of AC-electrode-based 
EDLCs was observed, and the relationships between the surface chemistry of modified ACs and capacitance of the corresponding AC-electrode-based supercapacitors was studied in order to obtain the highest capacitance.

\section{Experimental}

\subsection{Materials}

Cassava peel was obtained from cassava starch industry located near Surabaya. Cassava peel is suitable as the precursor for activated carbon preparation because of its high carbon content (28.90\%) (Sudaryanto et al., 2006). The cassava peel was repeatedly washed with distilled water to remove dust and other impurities, and then dried in oven for $24 \mathrm{~h}$ at $110^{\circ} \mathrm{C}$ to reduce the moisture content. Subsequently, dried cassava peel was crushed using a JANKE \& KUNKEL micro hammer mill to obtain cassava peel powder with particle size of $80 / 100$ mesh.

\subsection{Activated carbon preparation}

The preparation of activated carbon was carried out using chemical followed by physical activation. Chemical activation was performed by mixing the dried cassava peel with $\mathrm{KOH}$ solution at an impregnation ratio of 5:2 (mass $\mathrm{KOH}$ : mass cassava peel) and stirring at $323.15 \mathrm{~K}$ for $3 \mathrm{~h}$. The resulting slurry was dried in an oven for at least $24 \mathrm{~h}$ at $383.15 \mathrm{~K}$. The dried sample was placed in a pyrolysis reactor and heated at a carbonization temperature of $1023.15 \mathrm{~K}$ for $3 \mathrm{~h}$. The carbonization and chemical activation was conducted under inert condition under nitrogen (flowrate of $3 \mathrm{dm}^{3} / \mathrm{min}$ ).

The carbonization product was placed in a tubular furnace and heated to $1023.15 \mathrm{~K}$. The physical activation was conducted for $1 \mathrm{~h}$ under $\mathrm{CO}_{2}$ atmosphere (flowrate maintained at $2 \mathrm{dm}^{3} / \mathrm{min}$ ). The activated carbon products were washed sequentially with $0.5 \mathrm{~N}$ $\mathrm{HCl}$ to neutralize excess alkaline compounds. The samples were washed repeatedly with hot distilled water until the $\mathrm{pH}$ of the washing solution reach 6.5 and then washed with cold distilled water twice or thrice. The resulting activated carbon products were dried at $383.15 \mathrm{~K}$ for $24 \mathrm{~h}$ and stored in desiccators.

\subsection{Surface modification}

Surface modification of activated carbon was conducted with the oxidative chemical agents, 98 wt.\% $\mathrm{H}_{2} \mathrm{SO}_{4}, 65$ wt.\% $\mathrm{HNO}_{3}$, and 30 wt.\% $\mathrm{H}_{2} \mathrm{O}_{2}$ solutions. The activated carbons were mixed with these chemical agents with mass ratio 1:1 (mass of chemical agent: mass of activated carbon), and then shaken under constant rate (130 oscillations per minute) for $4 \mathrm{~h}$ at $338.15 \mathrm{~K}$. The resulting slurry was washed by distilled water repeatedly until the $\mathrm{pH}$ of washing solution reach 6.5 , and then dried in oven for $24 \mathrm{~h}$ at $383.15 \mathrm{~K}$.

\subsection{Physical characterization}

The physical characterization of activated carbons was conducted by using Nitrogen sorption method and Scanning Electron Microscopy (SEM). Nitrogen sorption (Sudaryanto et al., 2006) was carried out to determine the pore structure of the carbons, and scanning electron microscopy (SEM) analysis was conducted to observe the surface morphology of activated carbon samples.

The nitrogen adsorption/desorption isotherms were measured at $77.15 \mathrm{~K}$ (boiling point of nitrogen gas at atmospheric pressure) by a QuadraSorb SI. Prior to gas adsorption measurements, the carbon was degassed at $473.15 \mathrm{~K}$ in a vacuum condition for a period at least $24 \mathrm{~h}$. Nitrogen adsorption isotherms were measured over a relative pressure $\left(P / P_{0}\right)$ range from approximately $10^{-5}$ to 0.995 .

The BET surface area, pore volume and pore size distribution of the activated carbon were determined by using Brunauer-Emmett-Teller and Dubinin-Asthakov (DA) analysis software, which are available within the instrument, respectively. The BET surface area was determined by means of the standard BET equation applied in the relative pressure range of $0.06-0.3$. The total pore volume was calculated at a relative pressure of approximately 0.99 and at this relative pressure, all pores were completely filled with nitrogen gas. The DFT pore size distribution of all activated carbon samples were obtained based on nitrogen adsorption isotherms by using Quadrachrome Quadrawin software package with medium regularization.

SEM images were recorded by using JEOL JSM-6300F field emission SEM. A thin layer of platinum was sputter-coated on the samples for charge dissipation during FESEM imaging. The sputter coater (Eiko IB-5 Sputter Coater) was operated in an argon atmosphere using a current of $6 \mathrm{~mA}$ for $3 \mathrm{~min}$. The coated samples were then transferred to the SEM specimen chamber and observed at an accelerating voltage of $5 \mathrm{kV}, 8$ spot size, 4 aperture, and $15 \mathrm{~mm}$ working distance.

\subsection{Surface chemistry characterization}

The surface chemistry characterization of activated carbon was performed with the Boehm titration method (Prahas et al., 2006) and Fourier Transform Infra Red (FTIR) spectroscopy. The Boehm titration method can be described as follows: $0.5 \mathrm{~g}$ of activated carbon were placed to a series of flask which contain $50 \mathrm{ml}$ of $0.05 \mathrm{~N}$ sodium bicarbonate, sodium carbonate, sodium hydroxide, and hydrochloric acid. The flasks were sealed and shaken for $24 \mathrm{~h}$. After $24 \mathrm{~h}$, the solutions were filtered, and then $10 \mathrm{ml}$ of each solution was pipetted to a flask and was titrated with $0.05 \mathrm{~N}$ sodium hydroxide or hydrochloric acid, depending on the original solution used. The amounts of acidic groups on the activated carbon were calculated under the assumption that $\mathrm{NaOH}$ neutralizes carboxylic, lactonic, and phenolic groups; $\mathrm{Na}_{2} \mathrm{CO}_{3}$, carboxylic and lactonic; $\mathrm{NaHCO}_{3}$, only carboxylic group. The numbers of surface basic sites were calculated from the amount of $\mathrm{HCl}$ that reacted with the carbon. The reaction between the reagents and the acidic oxygenatedfunctional groups on the surface is based on the difference in acid/ base strength. The strength of acidic groups is as follow: carboxyl > lactone > phenol.

A qualitative analysis of activated carbon was conducted by obtaining FTIR transmission spectra of carbon samples with the $\mathrm{KBr}$ technique (Prahas et al., 2006). The technique was conducted by placing the $\mathrm{KBr}$ powder grinded with an agate mortar in the sample cup and then the powder surface evened by using the attached sample pressing bar. The powder is then mounted to the instrument to make a background measurement. The activated carbon sample was diluted with the $\mathrm{KBr}$ powder with the ratio of $10 \%$ and grounded with the agate mortar until it becomes fine particles to mix the both kinds. The mixed powder was placed in the sample cup and the powder surface also evened using the sample pressing bar. The mixed powder was mounted to the instrument to make a sample measurement in the transmittance\% $\mathrm{T}$ mode. The analysis was carried out by Shimadzu 8400S FTIR instrument in wavenumbers range of $4000-500 \mathrm{~cm}^{-1}$.

\subsection{Electrode preparation}

Activated carbon powders were mixed with distilled water, 20 wt.\% polyvinylidene difluoride (PVdF) as the binder, and $\mathrm{N}$ methyl-2-pyrrolidone (NMP) as the solvent. The resulting slurry was molded into a tube shape and dried at $373.15 \mathrm{~K}$ for $24 \mathrm{~h}$. The 
dried tube shape-electrodes were insulated with a PTFE (polytetrafluorene ethylene) sheet as the separator to prevent electric current bridging between electrodes in storage condition.

\subsection{Capacitance measurement}

The electrochemical measurements were investigated by galvanostatic charge-discharge using a battery-test apparatus (1284 Potensiostat/Galvanostat), and the stability and reversibility of capacitor were tested by cyclic voltammetry (GAT 4000 polargraphic/voltammetric). One type of electrochemical cell used is the 3-electrode cell. This cell consists of working electrode, reference electrode and counter electrode. In this research, $\mathrm{Ag} / \mathrm{AgCl}$ electrode (Argenthal) was used as reference electrode and a piece of platinum gauze with an exposed area equal to $4 \mathrm{~cm}^{2}$ as the counter electrode. A Luggin capillary was used to minimize errors due to the iR drop in the electrolytes. $0.5 \mathrm{M} \mathrm{H}_{2} \mathrm{SO}_{4}$ was used as electrolyte solution in the electrochemical cell and degassing was done with purified nitrogen gas for 25 min before measurements (Feng-Chin et al., 2006). The gravimetric specific capacitance was calculated by using the following formula (Yafei et al., 2008):

$\mathrm{C}=\frac{4 \cdot I_{d} \cdot \Delta t}{m \cdot w \cdot \Delta U}$

where $I_{d}$ is discharge current (Ampere), $\Delta t$ is discharge time (s), $\Delta U$ is difference of voltage in the time of $\Delta t$ during discharge (Volt), $\mathrm{m}$ is Total mass of the two electrodes (gram) and $w$ is mass fraction of activated carbon in the electrode.

\section{Results and discussion}

\subsection{Raw materials analysis}

The proximate analysis of cassava peel indicated that this raw material contains $28.7 \%$ of fixed carbon, $58.8 \%$ of volatile matter, $12.1 \%$ of moisture content, and $0.4 \%$ ash. The proximate analysis result shows that cassava peel has high carbon and low ash content, indicating that this precursor is a suitable raw material for the preparation of activated carbon. As the comparison, the fixed carbon content of several raw materials for activated carbon production is as follows: bamboo (16.60\%) (Choy et al., 2005), coconut shell (18.60\%) (Daud and Ali, 2004), palm shell (18.70\%) (Daud and Ali, 2004), durian shell (23.36\%) (Chandra et al., 2006), and rubber wood sawdust (23.38\%) (Srinivasakannan and Bakar, 2004).

\subsection{Physical characterization}

\subsubsection{The effect of activation on the pore characteristic}

Details of pore characteristic of activated carbon samples are given in Table 1. Fig. 1 shows the nitrogen adsorption isotherms at $77.15 \mathrm{~K}$ of the cassava peel carbon and its modified forms. From the result, it can be seen that the BET surface area of activated carbon derived from cassava peel was $1352 \mathrm{~m}^{2} / \mathrm{g}$, higher than commercial activated carbons available in Indonesia $\left(500-700 \mathrm{~m}^{2} / \mathrm{g}\right)$. This result indicates that the $\mathrm{KOH}-\mathrm{CO}_{2}$ activation greatly enhanced the pore development during the carbonization-activation process. Table 1 shows that the activated carbons pore structure is a

Table 1

Pore characteristic of activated carbons before and after modification.

\begin{tabular}{llllll}
\hline Sample & $S_{\text {BET }}\left(\mathrm{m}^{2} / \mathrm{g}\right)$ & $S_{\text {mic }}\left(\mathrm{m}^{2} / \mathrm{g}\right)$ & $V_{\text {tot }}\left(\mathrm{cm}^{3} / \mathrm{g}\right)$ & $V_{\text {mic }}\left(\mathrm{cm}^{3} / \mathrm{g}\right)$ & $V_{\text {mic }} / V_{\text {tot }}(\%)$ \\
\hline $\mathrm{NT}$ & 1352 & 876 & 0.579 & 0.356 & 61.5 \\
$\mathrm{H}_{2} \mathrm{O}_{2}$ & 1276 & 828 & 0.543 & 0.337 & 62.1 \\
$\mathrm{HNO}_{3}$ & 1186 & 772 & 0.501 & 0.312 & 62.3 \\
$\mathrm{H}_{2} \mathrm{SO}_{4}$ & 1336 & 866 & 0.569 & 0.352 & 61.7 \\
\hline
\end{tabular}

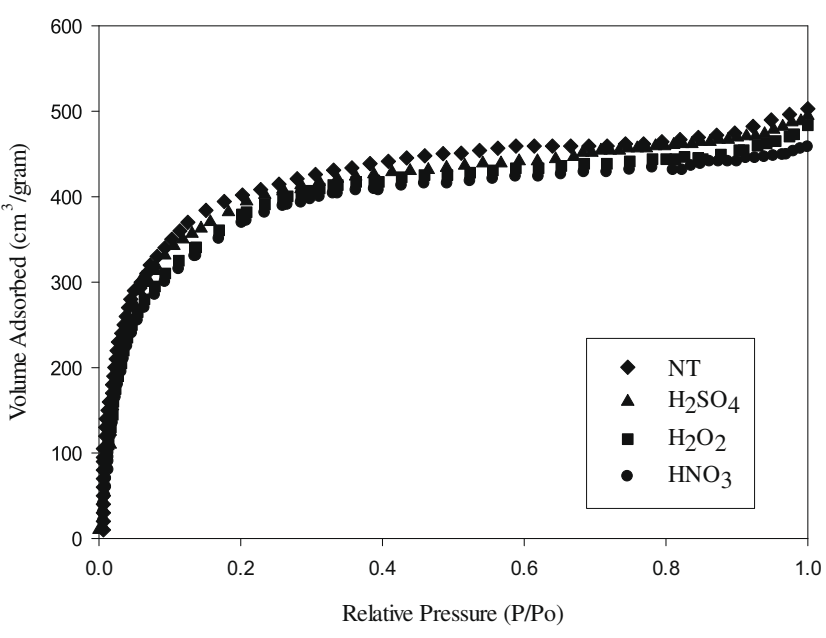

Fig. 1. Nitrogen adsorption isotherms of modified activated carbons derived from cassava peel.

combination between micropore and mesopore, with dominant micropore (61.5\%). This evidence also supported by the pore distribution of activated carbons obtained by using DFT method with medium regularization as shown in Fig. 2.

In chemical activation using $\mathrm{KOH}$ as activated agent, at temperature higher than $673.15 \mathrm{~K}$, the reaction between $\mathrm{KOH}$ and carbon occurs (Ganan et al., 2004; Sudaryanto et al., 2006) according to the following reaction:

$6 \mathrm{KOH}+\mathrm{C} \leftrightarrow 2 \mathrm{~K}+3 \mathrm{H}_{2}+2 \mathrm{~K}_{2} \mathrm{CO}_{3}$

The presence of metallic potassium will intercalate to the carbon matrix, resulting in widening of the spaces between carbon atomic layers and increasing the total pore volume (Ahmadpour and Do, 1997; Sudaryanto et al., 2006). At temperatures higher than $923.15 \mathrm{~K}$, the surface metal complex is responsible for further gasification, leading to the widening of micropore to mesopore (Ganan et al., 2004; Sudaryanto et al., 2006). The physical activation using $\mathrm{CO}_{2}$ gas was performed in order to maximizing the pore opening in the activated carbon and transforming some of the $\mathrm{KOH}$-activated carbon's micropore into mesoporous $(20 \AA<d<500 \AA$ ) structure (Feng-Chin et al., 2006). Therefore, by combining chemical activation and physical activation, a

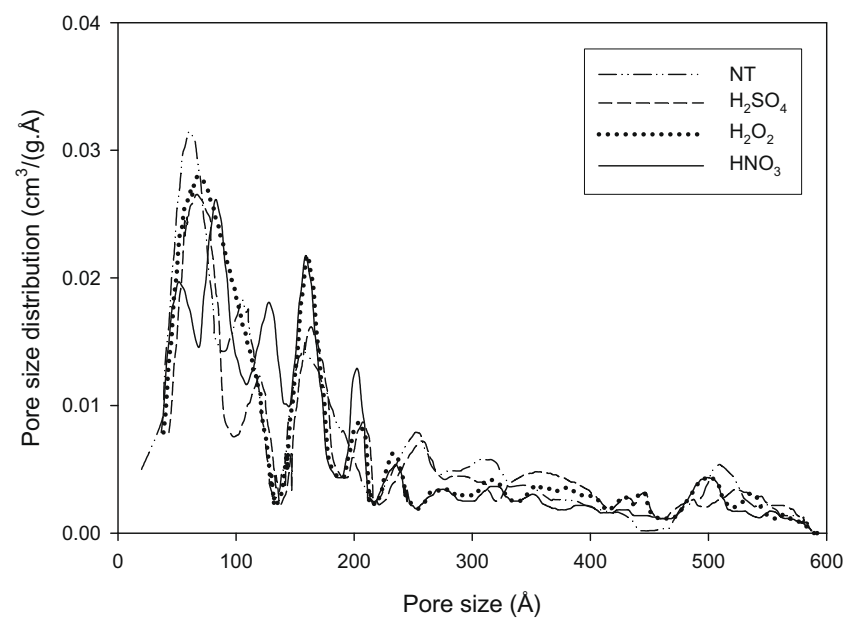

Fig. 2. Pore size distribution of modified activated carbons derived from cassava peel. 
combination between micropore-mesopore structures of activated carbon with certain percentage of micropore was obtained, which is desired for the electrode application.

For electrode application, it is desirable to obtain activated carbon with a combination of micropore and mesopore, because it has different role at different level of current density. At low current density $\left(<100 \mathrm{~mA} / \mathrm{cm}^{2}\right)$, micropores are dominant and enhance greater capacitance than mesopores. However, micropores are less stable than mesopores, the capacitance of micropores decreasing with the increase of discharge current density. At high discharge current $\left(100-200 \mathrm{~mA} / \mathrm{cm}^{2}\right)$, rapid movement of electrolyte ions is capable only in mesopores, so mesopores could exhibit high capacitance (Tamai et al., 2005).

\subsubsection{The effect of surface modification on the pore characteristic}

The effect of the surface modification on the surface area and pore development can be seen in Fig. 2 and Table 1. The surface modifications gave no significant effect, neither on the surface area and pore development of the activated carbons. The surface area of modified activated carbons changed only slightly after surface modifications were introduced. A decrease in surface area and pore volume due to the molecules or ions of modifying agents occupied some pores of activated carbon and produced some surface functional groups which reduced pore size or even partially blocked some pores (Yafei et al., 2008). Fig. 3 depicts the surface morphology of activated carbons before and after modification. It can be seen that similar surface morphology was observed for all activated carbons studied.

\subsection{Surface chemistry characterization}

Oxygen-containing groups such as carbonyl, hydroxyl, carboxyl, and quinine are some of the functional groups which give positive effects on the performance of activated carbon-based electrodes (Centeno and Stoeckli, 2006; Wenzhong et al., 2007; Yafei et al., 2008). Table 2 shows the amount of acid and basic sites on activated carbons before and after modification. It was found that the amounts of acidic functional groups were increased significantly after modification. The amount of carboxyl group before modification was $0.1925 \mathrm{meq} / \mathrm{g}$ whereas, after modification with $\mathrm{HNO}_{3}$ and $\mathrm{H}_{2} \mathrm{SO}_{4}$, the amount of this functional group was 0.5554 and $0.5104 \mathrm{meq} / \mathrm{g}$, an increase by $188.5 \%$ and $165.1 \%$, respectively. The number of other acidic functional groups, lactone and phenols, also increased.

The FTIR analysis was performed to determine the other functional groups, especially the oxygen-containing groups. FTIR spectra revealed the specific surface functional groups on activated carbons surface qualitatively based on the characteristic of absorbed energy for each bonds in certain groups (Putra et al., 2009). The FTIR spectra of activated carbons before and after modification are shown in Fig. 4. Fig. 4 reveals the increase of symmetrical and asymmetrical stretching vibration at wavelength ranges of $1000-1300,1550-1800,2300-2450$, and $3100-3700 \mathrm{~cm}^{-1}$, for all modified activated carbon samples. Based on Table 3 for FTIR assignments of functional groups on carbon surfaces, these bands were assigned to $\mathrm{C}-\mathrm{O}, \mathrm{C}=\mathrm{O}$ and $-\mathrm{OH}$ stretching vibration, respectively. The increase of these bands shows the increase of carbonyl, hydroxyl, carboxyl, quinine, and lactone groups on the surface of modified activated carbons, indicating that the surface modification with acidic and oxidative chemical agents developed the surface oxygen-containing groups on the activated carbons.

\subsection{Capacitance measurement}

The performance of the electrodes from modified activated carbons was investigated by using galvanostatic charge-discharge

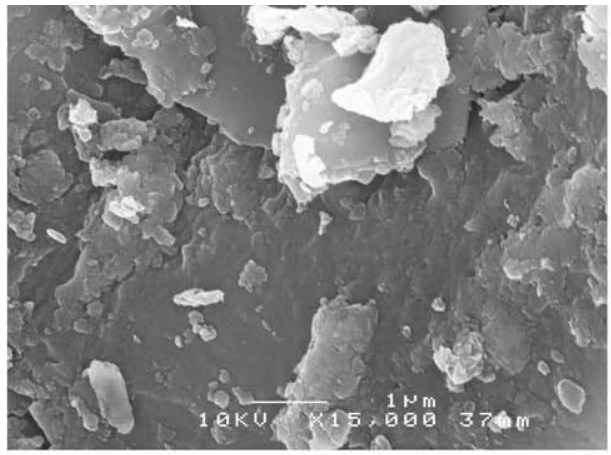

Non treatment

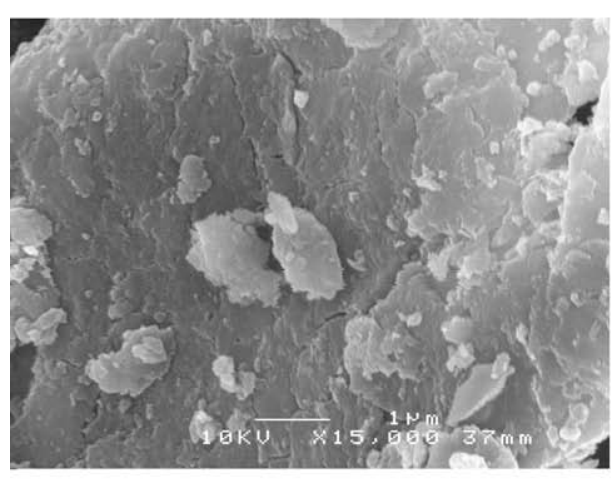

$\mathrm{HNO}_{3}$

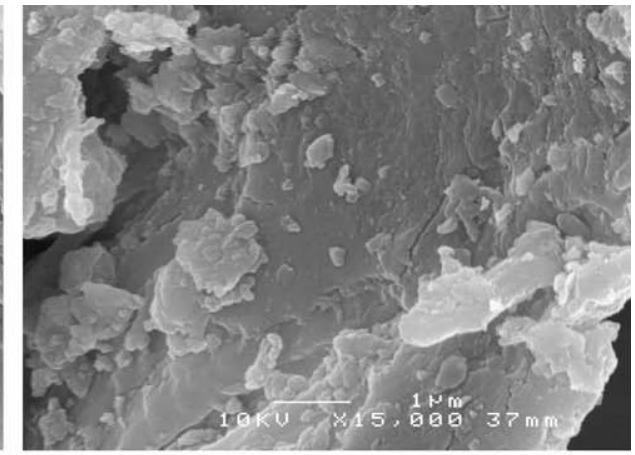

$\mathrm{H}_{2} \mathrm{O}_{2}$

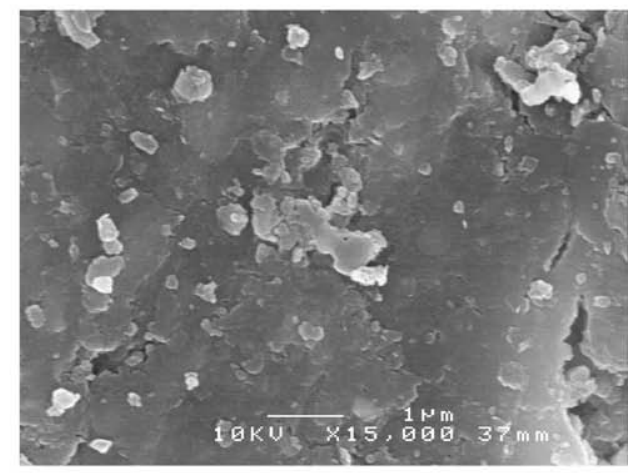

$\mathrm{H}_{2} \mathrm{SO}_{4}$

Fig. 3. Surface morphology of modified activated carbons from cassava peel. 
Table 2

Surface functional groups determined by Boehm titration.

\begin{tabular}{|c|c|c|c|c|c|}
\hline \multirow[t]{3}{*}{ Sample } & \multicolumn{5}{|c|}{ Functional groups on activated carbon (meq/g activated carbon) } \\
\hline & \multicolumn{4}{|l|}{ Acid group } & \multirow[t]{2}{*}{ Basic group } \\
\hline & Carboxylic & Lactonic & Phenolic & Total & \\
\hline Non treatment & 0.1925 & 0.5618 & 0.4106 & 1.1649 & 0.5047 \\
\hline $\mathrm{HNO}_{3}$ & 0.5554 & 1.0805 & 0.6481 & 2.2840 & 0.5156 \\
\hline $\mathrm{H}_{2} \mathrm{SO}_{4}$ & 0.5104 & 1.0364 & 0.6628 & 2.2096 & 0.4876 \\
\hline $\mathrm{H}_{2} \mathrm{O}_{2}$ & 0.3426 & 0.9769 & 0.5893 & 1.9088 & 0.4974 \\
\hline
\end{tabular}

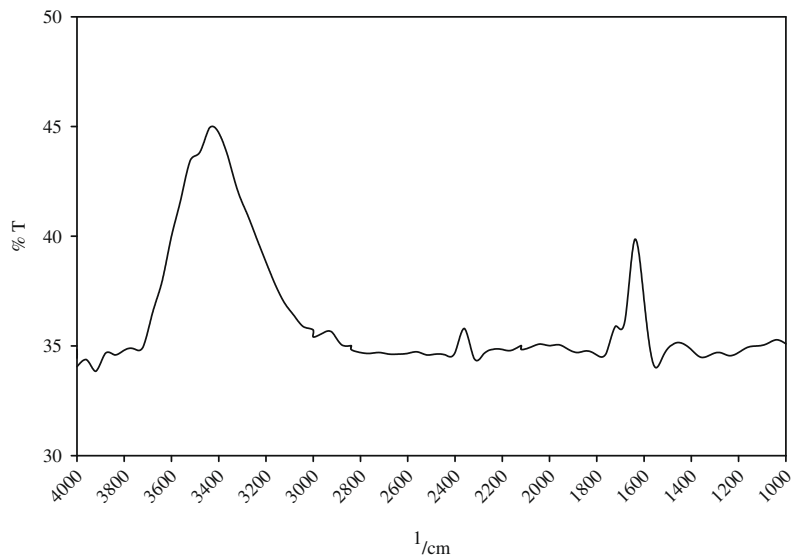

Non treatment

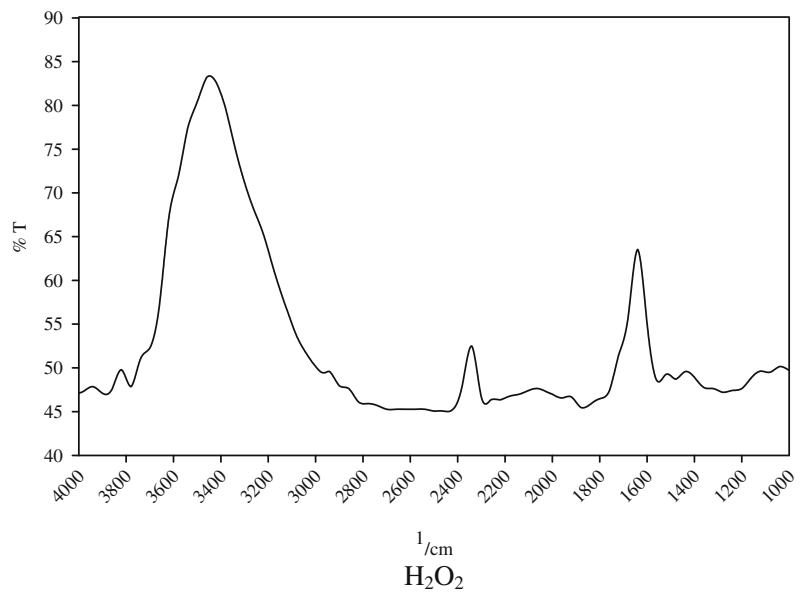

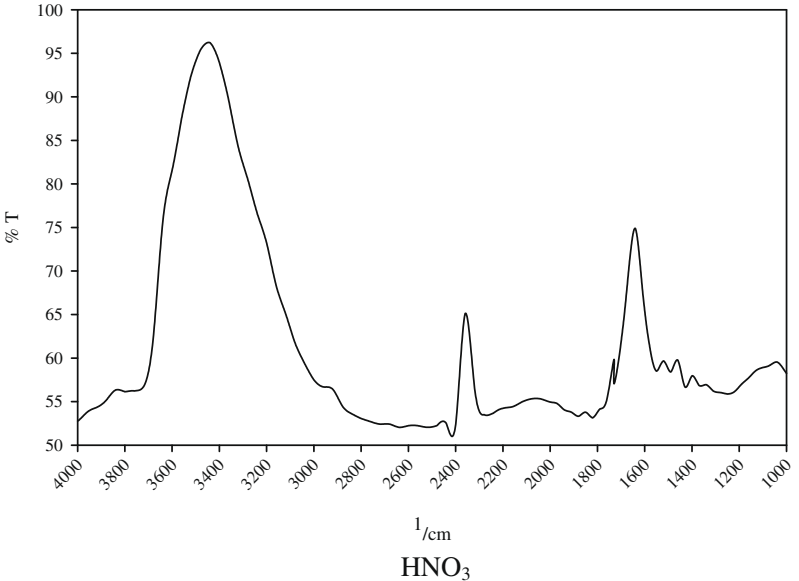

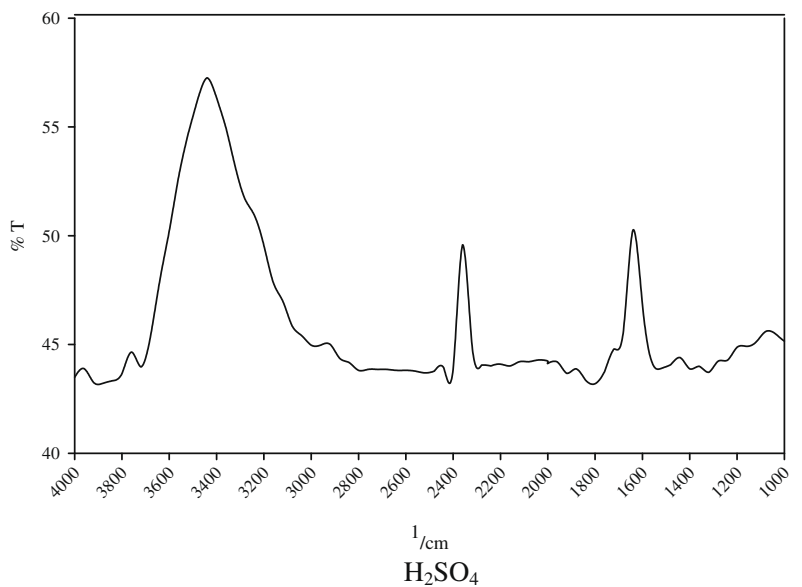

Fig. 4. The FTIR spectra of activated carbon before and after modification.

Table 3

FTIR assignments of functional groups on carbon surfaces.

\begin{tabular}{llll}
\hline \multirow{2}{*}{ Functional group } & \multicolumn{3}{l}{ Wavelength $\left(\mathrm{cm}^{-1}\right)$} \\
\cline { 2 - 4 } & $3700-2050$ & $2050-1500$ & $1500-1000$ \\
\hline Hydroxyl & $3650-3200$ & - & - \\
Quinine & - & $1680-1550$ & - \\
Carbonyl & - & $1780-1650$ & - \\
Carboxyl & $3300-2500$ & $1760-1665$ & $1200-1120$ \\
Lactone & - & $1790-1675$ & $1370-1160$ \\
\hline
\end{tabular}

and cyclic voltammetry. The principle of this method is to investigate the time of current charge and discharge process performed by the measured electrode. Fig. 5 shows the galvanostatic charge-discharge cycles of all activated carbon electrodes from 0 to $1 \mathrm{~V}$ in the acidic electrolyte $\left(0.5 \mathrm{M} \mathrm{H}_{2} \mathrm{SO}_{4}\right.$ solution). The result of each galvanostatic measurement was similar. All curves extended the isosceles triangle shape with the discharge time close to that of charge, reflecting high charge-discharge efficiency for all AC-electrodes. The difference of charge and discharge time was the factor that influenced the symmetricity of the isosceles triangle. The less the difference was, the more symmetric the isosceles triangle-shape and the more symmetric the triangle-shape, the higher the charge-discharge efficiency (Yafei et al., 2008). The high charge-discharge efficiency of capacitors indicated that carbon electrodes contacted well with electrolyte solution, or in other words the electrodes had a high hydrophilicity of their surface. Although the triangle shapes were similar, the details were different. The difference of each shape indicates the time needed for current charge and discharge during the measurement processes. The charge and discharge time of all modified AC-electrodes was longer than the unmodified AC-electrode, indicate that the modified ACelectrodes could be charged with more electrons or electrolyte ions than the unmodified one. 


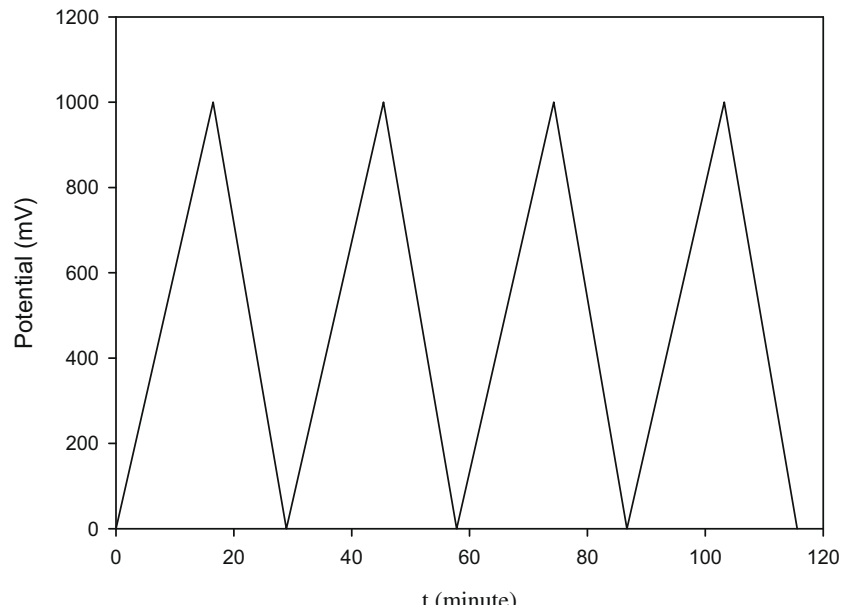

Non treatment

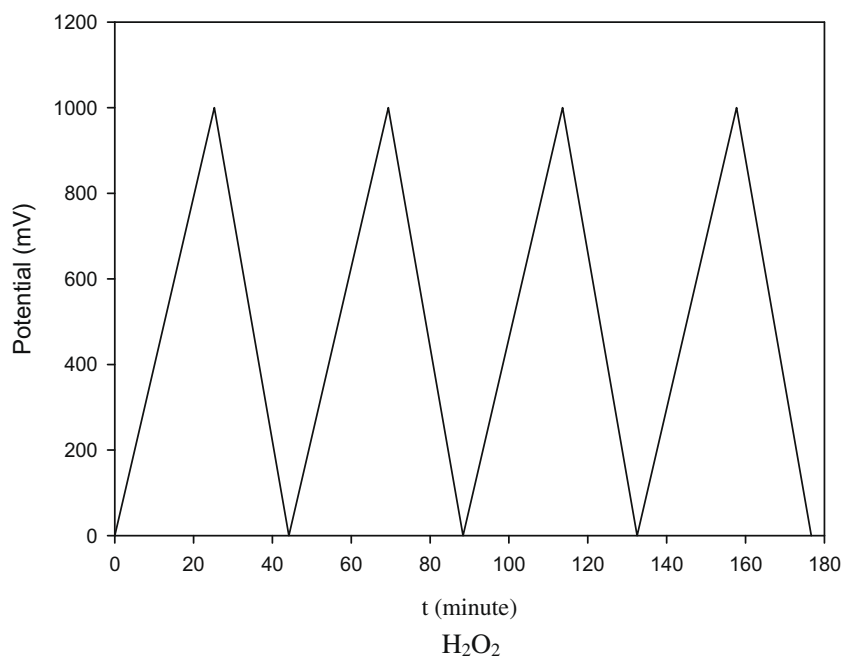

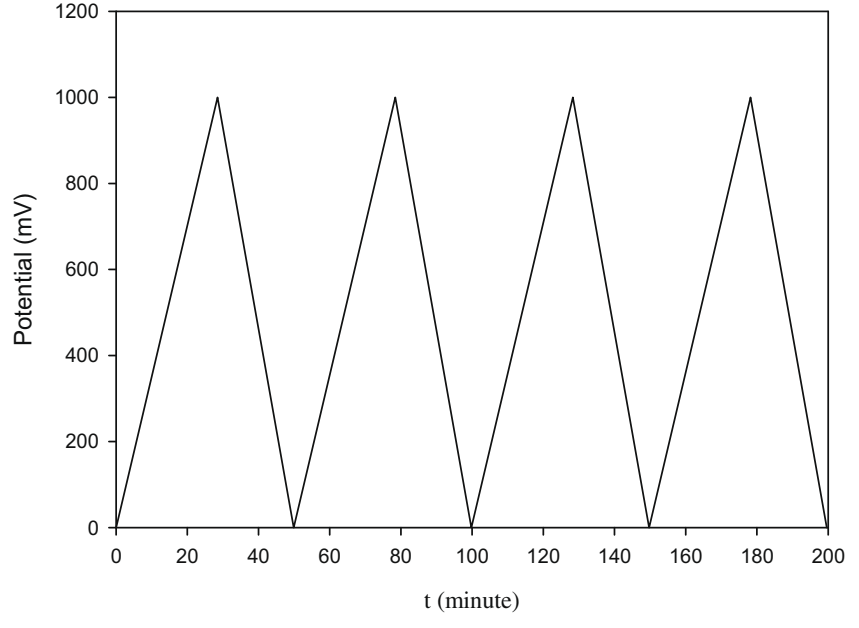

$\mathrm{HNO}_{3}$

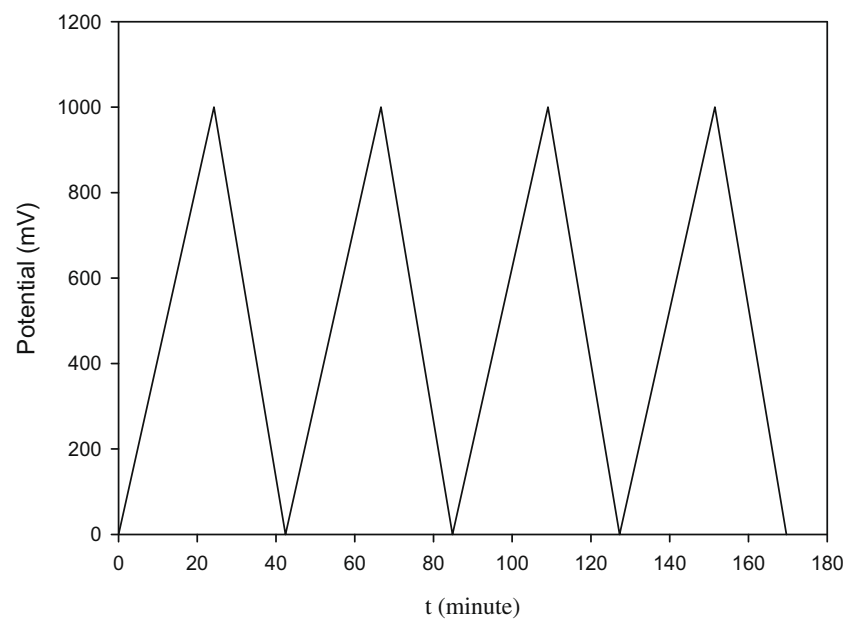

$\mathrm{H}_{2} \mathrm{SO}_{4}$

Fig. 5. Cyclic charge-discharge curves of activated carbon electrodes.

The specific capacitances of AC-electrodes as a function of discharge current were calculated according to Eq. (1) and the results are summarized in Table 4. From Table 4, it could be found that the specific capacitance of the modified AC-electrodes increased significantly compared with the unmodified one. The specific capacitance of unmodified AC-electrode was only $153 \mathrm{~F} / \mathrm{g}$, whereas the AC-electrodes modified by $\mathrm{HNO}_{3}$ and $\mathrm{H}_{2} \mathrm{O}_{2}$ are 264.08 and $240.67 \mathrm{~F} / \mathrm{g}$, increased by $72.6 \%$ and $57.3 \%$, respectively. It can be seen that the highest capacitance was reached by the $\mathrm{HNO}_{3}$-modified AC-electrode $(264.08 \mathrm{~F} / \mathrm{g})$, followed by the $\mathrm{H}_{2} \mathrm{O}_{2}(240.67 \mathrm{~F} / \mathrm{g}$ ) and $\mathrm{H}_{2} \mathrm{SO}_{4}(210.98 \mathrm{~F} / \mathrm{g})$ electrodes, respectively. This phenomenon showed that the modification with $\mathrm{HNO}_{3}$ increased the amount of oxygen-containing groups more than the other chemical agents.

Table 4

The specific capacitances of AC-electrodes.

\begin{tabular}{lll}
\hline Sample & $\Delta t(\mathrm{~min})$ & Specific capacitance $(\mathrm{F} / \mathrm{g})$ \\
\hline Non treatment & 12.40 & 153.00 \\
$\mathrm{HNO}_{3}$ & 21.40 & 264.08 \\
$\mathrm{H}_{2} \mathrm{SO}_{4}$ & 18.18 & 210.98 \\
$\mathrm{H}_{2} \mathrm{O}_{2}$ & 18.93 & 240.67 \\
\hline
\end{tabular}

This evidence is supported by the surface chemistry analysis (Section 3.3).

This result was compared with the performance of activated carbon-based electrode made from the other raw materials. Kim et al. (2006) prepared electrodes from bamboo-based activated carbon for an electrochemical supercapacitor. The specific surface area of bamboo-based activated carbon without any modification was $1025 \mathrm{~m}^{2} / \mathrm{g}$ and its specific capacitance reached $60 \mathrm{~F} / \mathrm{g}$ (Kim et al., 2006). Meanwhile, the specific capacitance of cassava peelbased activated carbon was higher by about $150 \%$, it reached $153 \mathrm{~F} / \mathrm{g}$ with a specific surface area of $1352 \mathrm{~m}^{2} / \mathrm{g}$ for the unmodified one. This comparison showed that the activated carbon derived from cassava peel has a higher specific surface area and better surface functional groups than the bamboo-based activated carbon.

Although the specific surface area of the modified was lower than that of unmodified activated carbon, a higher specific capacitance was achieved by electrodes made from modified activated carbons. This phenomenon showed that surface area was not the only factor that influenced specific capacitance, surface chemistry of activated carbon also played an important role in the performance of the activated carbon electrode.

The reactivity of the oxygen-containing groups is primarily due to the difference in electronegativity between oxygen and carbon 


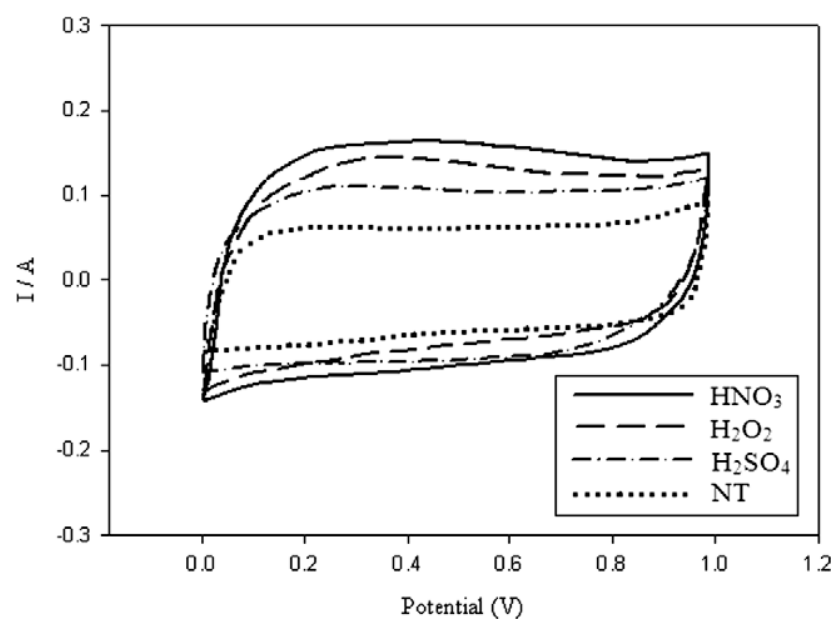

Fig. 6. Cyclic voltammogram of activated carbon electrodes at $20 \mathrm{mV} / \mathrm{s}$.

or hydrogen atoms. Oxygen has the greater affinity for electrons that makes oxygen more electronegative than carbon atom (in carbonyl and quinine group) or hydrogen (in hydroxyl group). It acquires a partial negative charge, becoming electron-rich; meanwhile the other atoms become electron-deficient, acquiring a partial positive charge. The difference in electronegativity in the oxygen-containing groups increased their bond's polarity. Therefore, the presence of the oxygen-containing groups on the surface of activated carbon enhanced the polarity of activated carbon and makes it more hydrophilic. Water, one of the polar compounds, has a low affinity for pure carbon, but it interacts strongly with oxygen containing surface groups. The strong affinity of water for the oxygen containing surface groups plays an important role for the performance of aqueous electrolyte capacitor, such as Electric Double Layer Capacitor (EDLC) (Centeno and Stoeckli, 2006).

Cyclic voltammetry was used to study the stability and reversibility of Electric Double Layer Capacitor. The cyclic voltammograms of the activated carbon electrodes at $20 \mathrm{mV} / \mathrm{s}$ potential sweep rate are shown in Fig. 6 . The experimental data showed that all of the electrodes were stable in the $\mathrm{H}_{2} \mathrm{SO}_{4}$ solution. Fig. 6 indicates that all curves have similar and symmetric rectangular shape between positive and negative sweep rate, indicating the good reversibility characteristic and high stability of EDLC during charge and discharge process of carbon electrode materials. The reversible reduction and oxidation reactions of functional groups introduced on the carbon surface might occur to generate pseudocapacitance during charge-discharge, so that the total capacitance of capacitor was increased (Yafei et al., 2008). The cyclic voltammogram of modified AC-based electrodes which had a broader area compared with the original AC-electrode, indicates that the capacitance of modified activated carbons is higher than the original one. This evidence supports the result of galvanostatic charge-discharge experiment. The $\mathrm{HNO}_{3}$ modified electrode had the broadest area, showing that this electrode had the highest capacitance, good reversibility and high stability.

\section{Conclusion}

A high performance capacitor's electrode was prepared from the modified activated carbon derived from cassava peel. The activated carbon was prepared from cassava peel with $\mathrm{KOH}-\mathrm{CO}_{2}$ activation and modified by surface treatment, using nitric acid, sulfuric acid and hydrogen peroxide. It was found that the preparation of capacitor's electrode from cassava peel-based activated carbon with surface modification by acidic and oxidative chemical agents is an effective process for the production of high performance and low cost activated carbon electrode materials for the Electric Double Layer Capacitor (EDLC). The surface modification gave significant effect on the performance of EDLC.

\section{References}

Ahmadpour, A., Do, D.D., 1997. The preparation of activated carbon from macadamia nutshell by chemical activation. Carbon 35, 1723-1732.

Centeno, T.A., Stoeckli, F., 2006. The role of textural characteristics and oxygencontaining surface groups in the supercapacitor performances of activated carbons. Electrochimica Acta 52, 560-566.

Chandra, T.C., Mirna, M.M., Sudaryanto, Y., Ismadji, S., 2006. Adsorption of basic dye onto activated carbon prepared from durian shell: studies of adsorption equilibrium and kinetics. Chemical Engineering Journal 127, 121-129.

Chmiola, J., Yushin, G., Dash, R., Gogotsi, Y., 2006. Effect of pore size and surface area of carbide derived carbons on specific capacitance. Journal of Power Sources 158, 765-772.

Choy, K.K.H., Barford, J.P., McKay, G., 2005. Production of activated carbon from bamboo scaffolding waste-process design, evaluation and sensitivity analysis. Chemical Engineering Journal 109, 147-165.

Daud, W.M.A.W., Ali, W.S.W., 2004. Comparison on pore development of activated carbon produced from palm shell and coconut shell. Bioresource Technology 93 63-69.

Feng-Chin, W., Ru-Ling, T., Chi-Chang, H., Chen-Ching, W., 2006. The capacitive characteristics of activated carbons-comparisons of the activation methods on the pore structure and effects of the pore structure and electrolyte on the capacitive performance. Journal of Power Sources 159, 1532-1542.

Frackowiak, E., Beguin, F., 2001. Carbon materials for the electrochemical storage of energy in capacitor. Carbon 39, 937-950.

Ganan, J., Gonzalez-Garcia, C.M., Gonzalez, J.F., Sabio, E., Macias-Garcia, A., DiazDiez, M.A., 2004. Preparation of activated carbon from bituminous coal pitches. Applied Surface Science 238, 347-354.

Kim, C., Lee, J.-W., Kim, J.-H., Yang, K.-S., 2006. Feasibility of bamboo-based activated carbons for an electrochemical supercapacitor electrode. Korean Journal of Chemical Engineering 24, 592-594.

Morishita, T., Soneda, Y., Tsumura, T., Inagaki, M., 2006. Preparation of porous carbons from thermoplastic precursors and their performance for electric double layer capacitors. Carbon 44, 2360-2367.

Prahas, D., Kartika, Y., Indraswati, N., Ismadji, S., 2006. Activated carbon from jackfruit peel waste: preparation, characterization, and its application on methylene blue adsorption. Journal of Environmental Protection Science 2, 1 10.

Putra, E.K., Pranowo, R., Sunarso, J., Indraswati, N., Ismadji, S., 2009. Performance of activated carbon and bentonite for adsorption of amoxicillin from wastewater: mechanisms, isotherms and kinetics. Water Research 43, 2419-2430.

Qu, D., Shi, H., 1998. Studies of activated carbons used in double-layer capacitors. Journal of Power Sources 74, 99-107.

Srinivasakannan, C., Bakar, M.Z.A., 2004. Production of activated carbon from rubber wood sawdust. Biomass and Bioenergy 27, 89-96.

Sudaryanto, Y., Hartono, S.B., Irawaty, W., Hindarso, H., Ismadji, S., 2006. High surface area activated carbon prepared from cassava peel by chemical activation. Bioresource Technology 97, 734-739.

Tamai, H., Kunihiro, M., Morita, M., Yasuda, H., 2005. Mesoporous activated carbon as electrode for electric double layer capacitor. Journal of Materials Science 40, 3703-3707.

Tashima, D., Kurosawatsu, K., Sung, Y.-M., Otsubo, M., Honda, C., 2007. Surface modification of nanoporous materials for electric double layer capacitors application. Material Chemistry and Physics 103, 158-161.

Wenzhong, S., Zhijie, L., Yihong, L., 2007. Surface chemical functional groups modification of porous carbon. Recent Patent in Chemical Engineering 1, 27-40.

$\mathrm{Xu}$, B., Wu, F., Chen, R., Chao, G., Chen, S., Zhou, Z., Yang, Y., 2008. Highly mesoporous and high surface area carbon: a high capacitance electrode material for EDLCs with various electrolytes. Electrochemistry Communications 10, 795-797.

Yafei, L., Zhonghua, H., Kun, X., Xiangwei, Z., Qiang, G., 2008. Surface modification and performance of activated carbon electrode material. Acta Physico-Chimica Sinica 24, 1143-1148.

Yansu, W., Chengyang, W., Chunyu, G., Zhiqiang, S., 2008. Influence of carbon structure on performance of electrode material for electric double layer capacitor. Journal of Physics and Chemistry of Solid 69, 16-22.

Yoshida, A., Tanahashi, L., Nishino, A., 1990. Effect of concentration of surface acidic functional groups on electric double-layer properties of activated carbon fibers. Carbon 28, 611-615. 